\title{
Introduction to the Small Satellite Revolution and Its Many Implications
}

\author{
Joseph N. Pelton and Scott Madry
}

\section{Contents}

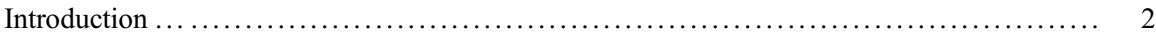

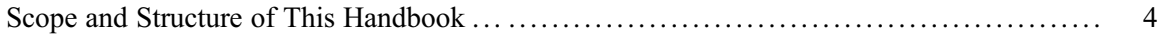

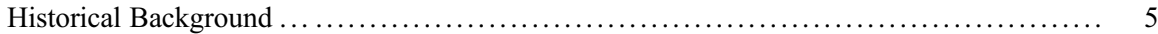

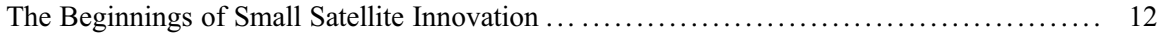

New Ways of Thinking About How to Design, Manufacture, and Launch Satellites ......... 15

The Many Different Types of Small Satellites ................................... 17

The Challenges of Design, Manufacture, and Testing of Smallsats .................... 22

Key Challenges for Small Satellite Constellations Related to Regulatory and International

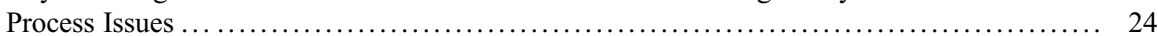

Regulatory and Technical Innovations to Cope with Orbital Space Debris .............. 27

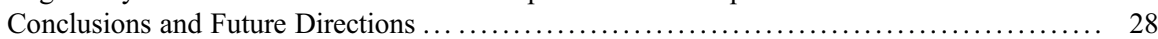

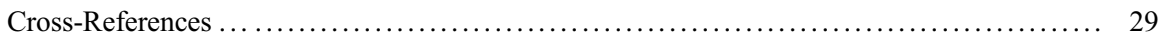

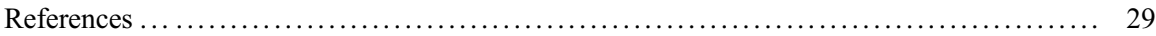

\section{Abstract}

This chapter provides a broad introduction to this Handbook on small satellites. It offers information as to why this Handbook was created and its primary uses. It provides guidance as to the structure of the Handbook and its Appendices and a useful information as to how the text of this Handbook and its references can be employed to understand about the history, the technology of small satellites, ground stations and systems for users of these small satellites, the operation of these facilities, launch services, as well as definitions concerning the many different types of these small satellites that exist today. It also provides information, explanations, and definitions about the economic, legal, policy, and

J. N. Pelton $(\bowtie)$

International Space University (ISU), Strasbourg, France

e-mail: joepelton@verizon.net

S. Madry

University of North Carolina, Chapel Hill, NC, USA

e-mail:madrys@email.unc.edu 
regulatory aspects of these systems. It has an entire section devoted to providing information about the many diverse and growing aspects of applications and services that can be used by employing small satellites and how they are uniquely able to provide some of the newer and more entrepreneurial space-based services. There is a chapter that relates the uses of small satellites as a means to achieve the United Nations Sustainable Development Goals (SDGs) for 2030. In short this Handbook seeks to provide a comprehensive set of information about all aspects of smallsats, their uses and applications, the related ground systems, their launch and operation, as well as related economic, legal, policy, business, and financial aspects of these new types of space systems. Finally it seeks to address key issues and challenges for the future that include frequency allocation and management, orbital space debris, space traffic control and management, as well as competitive technological, business, economic, and financial issues. It also notes that the COVID-19 pandemic will have a major impact on the world economy and that this will include a major impact on the small satellite and launch industries. In short there will likely be a number of bankruptcies in this field as a direct or indirect consequence, but these setbacks do not impact the innovative technologies or other information presented in this handbook.

\section{Keywords}

Cubesats - Disruptive technologies - Electronic beam-forming ground antennas · Geosynchronous Earth orbit (GEO) · High-throughput satellites (HTS) · Launch vehicles · Low Earth orbit (LEO) - Medium Earth orbit (MEO) - Orbital space debris · "Smallsats" - Satellite constellations · UN Sustainable Development Goals · Global Navigation Satellite Services (GNSS) · Precision Navigation and Timing (PNT)

\section{Introduction}

There are many excellent books and articles now available on all aspects of small satellites. This is a field that has exploded in activity and global interest in the past decade. There are a wide range of individual sources about the technology, others on the applications and services, and yet others about the economics, launch arrangements, policy and regulation, and social and political consequences. Yet there has not previously been a comprehensive and interdisciplinary source of information that collects all of this information together in a holistic way - until now. This Handbook of small satellites seeks to provide a complete overview of all aspects of the small satellite field.

Thus leading experts from around the world have been recruited to provide in one reference source the latest technical, operational, financial, regulatory, and service information about small satellites on a global basis. This provides information from the smallest femtosat (below $100 \mathrm{~g}$ in size) up to the largest and most sophisticated small satellites that range in size up to 500-600 kg in mass. Such "smallsats" are being deployed in so-called mega-LEO satellite constellations that OneWeb, Planet, 
SpaceX, Telesat, Boeing, LeoSat, Comstellation, and others are deploying or proposing to deploy in the next few years.

The COVID-19 pandemic that occurred in 2020 has caused health and economic consequences of staggering worldwide consequences. This horrific pandemic will impact the small satellite and launch industry in the months ahead. Already LeoSat and OneWeb small satellite constellations have declared bankruptcies, and others will follow. There will be more failures of small satellite constellations, launcher companies, and other associated space services companies. Despite these economic failures, the innovative new small satellite technologies, the new more efficient launch systems, the new ground systems, and the many other innovations discussed in this Handbook remain valid and very useful sources of new enterprise in this field. In the late 1990s, the original small satellite constellations saw major economic collapses. The economic failures constituted by Iridium, Globalstar, ICO, and Orbcomm made a huge impact on satellite development and the ready access to capital financing for some time. Yet recovery was achieved in the years that followed. The same seems likely to occur. Despite these setbacks the information in this Handbook remains useful and quite relevant.

Thus this Handbook provides information about the historical development of "smallsats" as well as an explanation of the various types of "smallsats" that are being developed and launched today. It also provides the latest information about the space and ground system technology and the relevant applications and services, as well as the economic, policy, regulatory, legal, business, and social aspects of this burgeoning field of space activity.

This book seeks to provide information from the perspective of all those interested in space satellites. It thus seeks to provide useful information for the student experimenter and for those undertaking smallsat projects for civilian space agencies and military and defense agencies. It also provides useful information suitable for so-called "NewSpace" business enterprises engaged in small satellite-related businesses as well as the political and legal officials that provide the regulatory oversight for small satellite systems. This includes information about the efficient allocation and oversight of the frequency spectrum needed for these systems to operate effectively.

This Handbook on small satellites addresses key issues such as orbital space debris, end of life removal of small satellites from orbit, new ways to design and build satellites, frequency spectrum coordination, as well as innovative ways to address the problems of jamming and interference. It even addresses new approaches to the efficient use of space resources and satellites such as placing hosted payloads on larger satellites. It addresses the new opportunities for achieving cost-efficient "space-like" services from high-altitude platform systems (HAPS).

It is the hope of all the contributors to this reference work and from the scores of participants from around the world that this Handbook will be found helpful. In particular it is hoped that the many articles that follow, plus the many references to books and articles found in endnotes, can serve as a useful guide to the design, manufacture, deployment, use, oversight, and business developments needed for the future success of "small satellites" enterprises around the world. The burgeoning number of smallsat systems and launches represent a powerful element in the growth 
of "NewSpace" or "Space 2.0" ventures. These NewSpace businesses have sprung up around the world. They are now giving new impetus to a rapidly expanding space industry. In time these space enterprises will expand to become a "trillion dollar" industry. These NewSpace industries will help sustain a growing world economy. In short, "smallsats" will touch everyone. They will aid enterprises that range from the ecology to banking, from fishing to mining, and from airline travel to health care and education.

This is not to say that "smallsats" will replace large satellites. Large and powerful high-throughput satellites, for instance, are best positioned to provide broadcast television services to small low-cost satellite dishes. Other satellite services, such as Precision Navigation and Timing (PNT) services and those designed to provide military- and defense-related intelligence, will likely continue to require larger space and high-power levels as well. The bottom line is that different services and applications will likely require different types of satellites of varying sizes and power levels.

The technical, operational, and economic reasons for the "right type" of satellite in terms of size, power level, architecture, and mass will be explained in later sections of this chapter. Instead of a "replacement" of large and powerful satellites, we will see a sort of coexistence of all types of satellites from tiny and small to medium and large scale. Nevertheless, small satellites seem likely to provide an everexpanding range of services in the coming decade.

Even in the area of larger satellite design and deployment, innovations that come from the smallsat field seem likely to have a major impact. Technology from the field of scientific satellites has been traditionally transferred over to the area of application satellites. For instance, the three-axis body-stabilized satellite with enhanced pointing accuracy and enhanced solar power efficiencies that was first developed for planetary research missions was rapidly transferred to the field of application satellites. The same transfer of technological innovation will also be the case with "smallsat" innovations. Miniaturization, enhanced testing, or manufacturing efficiency techniques that come from "smallsat" programs are being and will be shared and transferred to "large satellite" programs. The case of Canada's new threesatellite RADARSAT Constellation is perhaps an excellent case in point.

\section{Scope and Structure of This Handbook}

This Handbook of small satellites seeks to provide a comprehensive overview of the small satellite field. It thus addresses the history of small satellites and provides insight into the technology and its evolution over time both in terms of the spacecraft, the tracking, telemetry, and command aspects of its operation, and the corresponding changes to the ground segment for users of this technology. Such innovations represent a critical part of the evolutionary path that has furthered and enabled the feasibility and economics of small satellites. Key new features such as improved and accelerated testing processes, the use of hosted payloads, high-altitude platform systems, active debris removal, on-orbit servicing, new ground systems with electronic tracking capabilities, and more will be addressed as well. 
After the technological and operational aspects are presented, the next section will address the key aspects of small satellite design, engineering, and manufacture. This will also address business-related concerns such as contracting, resiliency and sparing philosophy, and protection of intellectual property rights.

The next section addresses the great complexity of applications and services and the many different types of small satellites that can be deployed to meet the needs associated with the increasingly diverse range of services as well as the many types of organizations and units that are now pursuing the active deployment and use of small satellites. This even includes the use of small satellites by defense agencies and military ministries. The distribution of smallsat uses for 2018 as developed by Bryce Space and Technology consulting shows the following breakdown. This was $11 \%$ for communications, $41 \%$ for technology development and verification, $2 \%$ for military and intelligence purposes, $37 \%$ for remote sensing, $6 \%$ for scientific purposes, and 3\% for other or unknown uses. But this snapshot of current uses does clearly show current trends. The overwhelming usage that is shown by either national filings or filings with the International Telecommunication Union suggests that communications or networking applications will vault into the number one purpose in the coming years as mega-LEO systems are deployed for this purpose in the future (Bryce Space \& Technology 2019).

The final major element of the Handbook addresses the economic, legal, and regulatory issues and constraints that are concerned with the increasingly complex field of small satellites.

This is followed by the conclusion section that assesses all of the current trends, major technical, economic, social, and regulatory issues that are pending, and how this relates to the small satellite revolution and Space 2.0 industries. This synoptic final analysis provides a coherent overview of the field of small satellites around the world. This final analysis relates the key trends in the area of small satellites and its ups and downs to broader world goals and objectives such as the United Nations' 17 Sustainable Development Goals (See Fig. 1) and the work of the Davos World Economic Forum.

There are also a series of appendices that provide information on small satellite projects and activities as well as information related to regulatory actions and policies as well as a glossary of terms. In light of the transitory nature of developments in this fast-moving field, an effort is made to provide website addresses with current URLs so that the current status of projects can be obtained from the official site for small satellite projects. Collectively this Handbook should provide comprehensive information about every aspect of the fast-moving world of small satellites.

\section{Historical Background}

Small satellites are not new. The very first satellites that were launched into orbit in the late 1950s and early 1960s such as Sputnik I, Explorer 1, Oscar 1, SCORE, Relay, and Syncom were all "small satellites." At the time, there was of course no thought being given to whether spacecraft were "small," "medium," or "large" in 


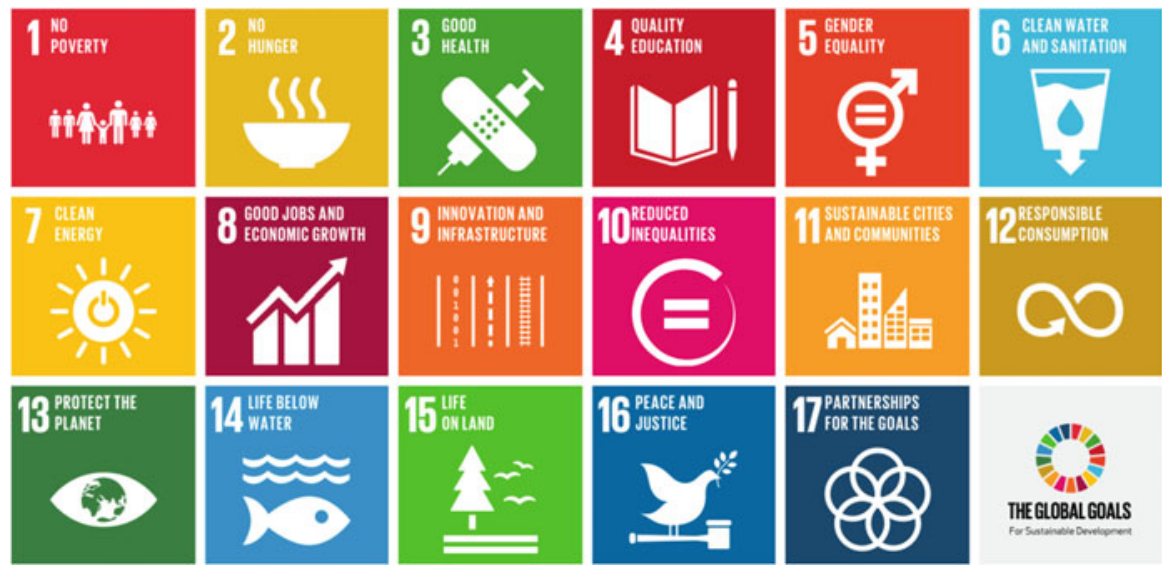

Fig. 1 New capabilities offered by smallsats can benefit developing nations and the UN Sustainable Development Goals (Graphic courtesy of the United Nations)

size in those pioneering years. The lift capacity of the launch vehicles in those days, especially those in the USA, could only launch what are now considered small satellites. Thus in the earliest days, the antennas were often simple dipole antennas, and the power was quite limited (see the Oscar 1 satellite shown in Fig. 2).

These very early satellites typically did not exceed the volume of a large beach ball, and their mass was only a few kilograms. This was because these early satellites were largely experimental in nature, limited to launch vehicle capacity, and expectations were accordingly low as to spacecraft size.

These first satellites were thus largely designed to prove that such technology could truly function in outer space. There were limited expectations as to what capacity these spacecraft might make in terms of actually offering commercial services.

Even the first "operational satellites" such as Early Bird (Intelsat 1), Molniya 1, the Initial Defense Satellite Communication System (IDSCS) satellites, and ANIK-1 were relatively modest in their throughput capabilities (i.e., typically less than a few 100 telephone circuits). These early satellites were also quite low in power (i.e., less than 100 watts) and had rudimentary stabilization systems. These earliest satellites accordingly required sophisticated ground stations with huge aperture antennas to receive and transmit signals. They had to be of this size and power to be able to communicate effectively with these early small and low-powered satellites as they circled the Earth.

The first Intelsat Standard A Earth stations that operated in tandem with the first few generations of Intelsat satellites, for instance, were gigantic steerable antenna systems. These gigantic facilities were $30 \mathrm{~m}$ (i.e., nearly $100 \mathrm{ft}$ ) in diameter and weighed perhaps several tens of tons. These stations were also expensive to operate. These mammoth facilities required staffing on a continuous $24 \mathrm{~h}$ a day and on 7 days a week basis with a staff of perhaps 50-60 people. They had cryogenic cooling 
Fig. 2 The Oscar 1 amateur ham radio satellite was an early "smallsat" (Graphic courtesy of the Amateur Satellite Organization (AMSAT))

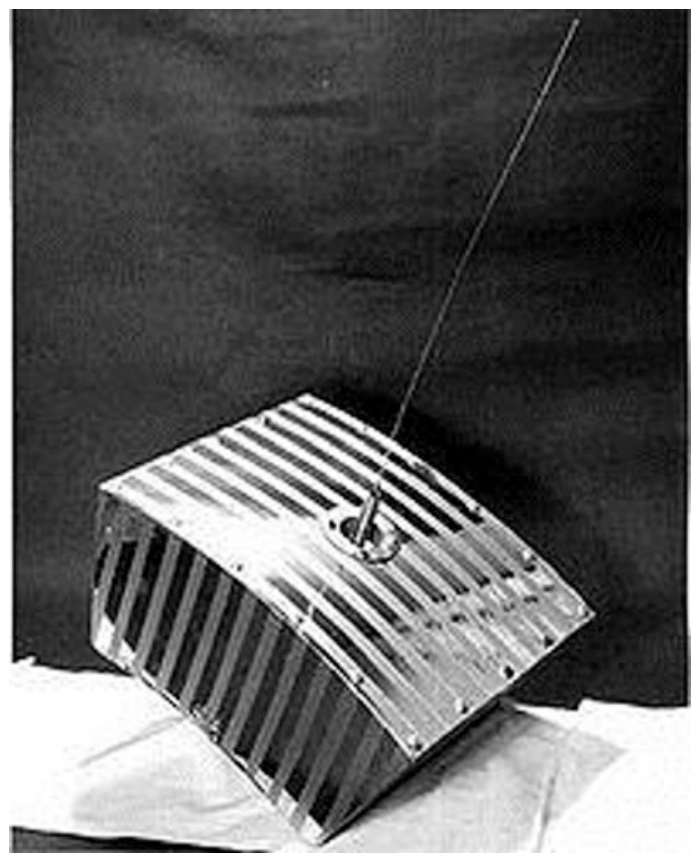

systems to boost the receiving sensitivity of the antenna's electronics and massive steering capabilities that were very exact. These huge antenna systems were thus almost like radio telescope systems and cost in the range of \$5 million to \$10 million dollars apiece. This was at a time when a dollar was valued at three to four times as much as it is today. In the earliest days of satellite communications, the largest investment was thus in the ground stations and not the satellites (Pelton 2003).

But this changed rather quickly in the years and decades to follow.

This major trend in satellite development became known as technology inversion. This phrase referred to the fact that the satellites moved to become more complex and massive. Ground antennas on the other hand became simpler and smaller. Each new generation of the Intelsat satellites, for instance, quickly grew in mass, power, antenna size, and technical sophistication such as adding three-axis stabilization. This allowed precise pointing of the satellite antenna system toward specific locations on Earth as high-gain antennas were added to the satellites.

The objective of this trend was to allow ground antenna systems to be smaller and less costly and to achieve higher throughputs for communications satellites. And communication satellites indeed represented the number one practical application for the satellites that were deployed in the 1960s, 1970s, 1990s, and 2000s.

This 50 -year trend from the 1960 s to the 2010s is clearly depicted in Fig. 3. The figure below shows this process of technology inversion. During this five-decadelong evolution, the satellites became bigger, higher-powered, and more capable, 


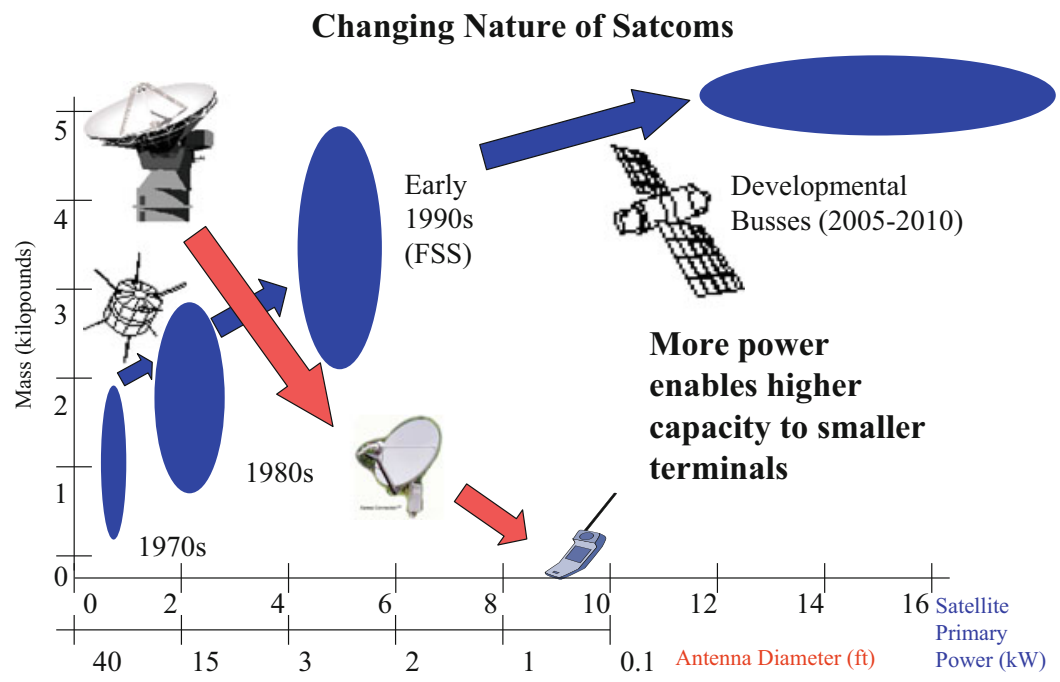

Fig. 3 The technology inversion: satellites grew in size and ground systems shrank (Graphic courtesy of the author)

while the ground stations kept shrinking in cost and size. The current smallsat revolution is serving to reverse some aspects of this longer-term trend.

The primary application for satellites during this time was for satellite communications. And when satellite communications were demonstrated to be possible from geosynchronous orbit (sometimes known as the Clarke Orbit in honor of Arthur C. Clarke who first proposed this type of orbit for global communications in 1945), there was a sudden and indeed voracious demand for bigger and better comsats to fill the demand for international communications, global television broadcasts, and networking associated with international trade, which outstripped the capacities of international coaxial cable networks. The increasing cost efficiency of each new generation of satellites, improved launch vehicle capabilities, improvements in ground antenna systems, the demand for television channels everywhere, and need for long-distance communications around the world led to higher and higher capacity satellites and indeed more different types of satellite networks.

Over a period of some 50 years, the trend in the satellite world was predominately defined by the growth profile shown in Fig. 3. The satellites, especially those for communication services, grew bigger and bigger. The large-scale solar arrays on these increasingly more powerful satellites generated much more power, and there were also larger battery systems to provide backup power during periods of eclipse. The satellites evolved to have three-axis body stabilization that allowed very precise pointing capabilities and also allowed the solar arrays to be constantly oriented to get the greatest amount of exposure to the sun. This, in turn, allowed very large aperture antennas on the satellites to be deployed, so they could be constantly pointed to specific locations on the Earth. This, in turn, enabled increasingly concentrated and 
tightly spot beams and the ability to reuse spectrum multiple times since the spot beams could be geographically isolated from one another.

These design innovations in the antenna systems to create tightly defined spot beams as they were added to these much larger satellites also saw the addition of polarization isolation in the transmitted beams. These innovations allowed more and more intensive reuse of radio-frequency spectrum. The more powerful and more capable satellites allowed the use of smaller and less expensive ground antenna systems.

The mass, size, and power of satellites thus grew and grew. Although the satellites in the sky were more expensive, the ever-expanding number of user antennas on the ground could be smaller and smaller and much less costly to acquire and eventually automated so that no staff was needed.

The increase in the critical dimensions of the satellites increased their size and power by a factor in the range of 200 times, but the throughput and lifetime performance increased proportionally to a much greater degree. The giant communication satellites of today such as the Intelsat Epic Satellites, the ViaSat-1 and ViaSat-2, and the EchoStar Jupiter satellites have tens of thousands the times of throughput capacity and ten times greater lifetime of the earlier satellites when the field of satellite communications began (see Fig. 4).

There has been a staggering increase in performance that is only paralleled by the increase in the performance of computers over the past 50 years. The increase in cost

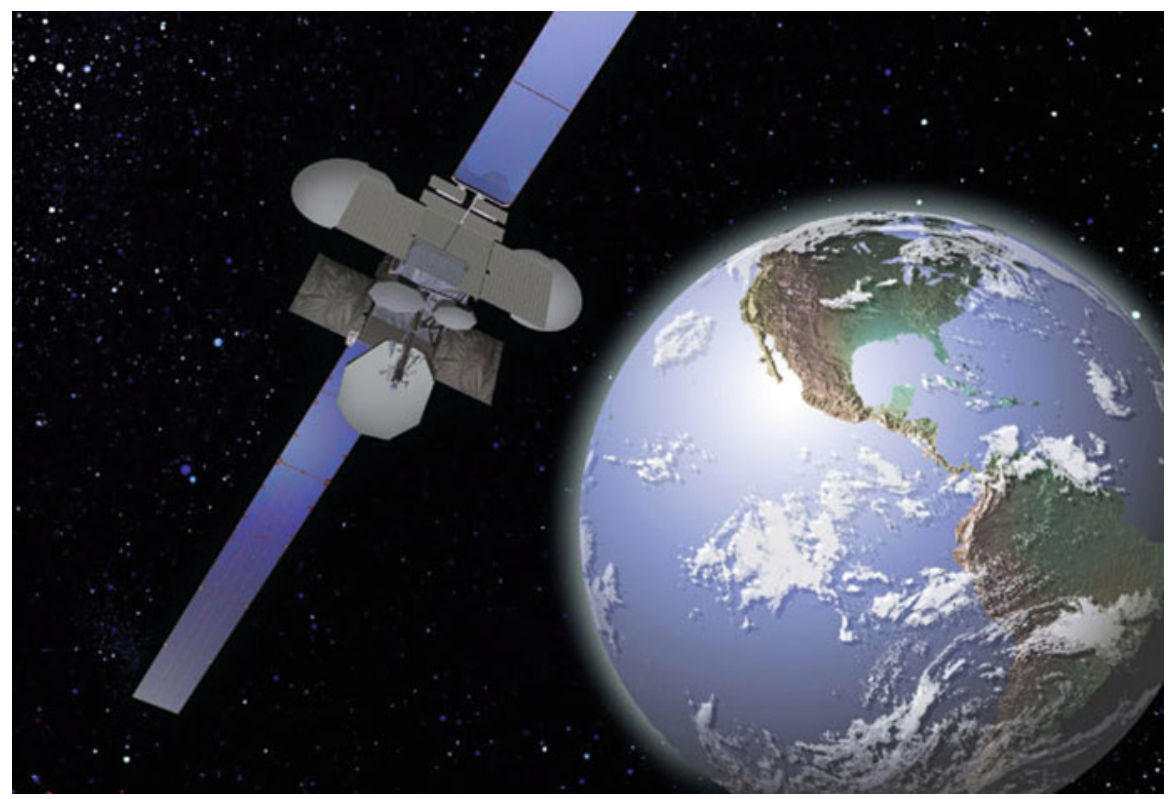

Fig. 4 The ViaSat-2 satellite can transmit at a rate of 160 gigabits/s (or the equivalent of 10,000 times the capacity of the Early Bird Satellite of 1965), and its lifetime is 10 times longer (Graphic courtesy of ViaSat) 
efficiency and improved performance of communication satellites is staggering when one considers "then" versus "now." The Intelsat 1, known as Early Bird, launched in 1965, had a capacity of only a few 100 voice circuits compared with the millions of voice circuit or the thousands of television circuit capabilities demonstrated by today's high-throughput satellites.

In the mid-1980s and 1990s, however, the model of how satellites might evolve for the future began to develop new branches and new schools of thought. CTA and Orbital ATK (now owned by Northrop Grumman) developed a smaller geosynchronous satellite platform with lower power known as the GEOStar-1. This new smaller GEO satellite formed the basis of new satellite communications ventures for developing countries. New platforms of different sizes were developed for different types of users with different levels of service requirements.

Other companies, however, took the idea of smaller commercial satellites in a whole new direction entirely. They began designing constellations of many smaller satellites deployed in low Earth orbit (LEO) for various purposes. These included the Iridium satellite system, the Globalstar satellite system, and the ICO system that were to provide land mobile satellite services to handheld satellite phones. Orbital ATK came up with the idea of even smaller LEO satellites for message relay, and this system was known as Orbcomm. Yet another company that was backed by Craig McCaw and Bill Gates thought it could utilize new frequency spectrum in the millimeter wave spectrum (i.e., the Ka-band) to create a massive so-called "megaLEO" system. This system was first known as the Calling Satellite System and then renamed Teledesic. This system was to have had 840 satellites plus 80 spares. This system design was to have many innovative features such as the use of phased array antennas on the satellite so as to create the effect of permanently "painted" beams on the ground so that the ground system could be simplified. Thus all of the pointing and switching of beam would be done on the satellite (Teledesic History n.d.). During the 1990s and 2000s, there were many different satellite designs, for many types of satellite services, in different frequency bands, with quite different types of ground systems, and different schemes for their launch into different types of orbits.

What all of these systems had in common was to design, manufacture, and launch a large number of "smaller" satellites into large-scale constellations - mostly in low Earth orbit (LEO). Instead of deploying large and expensive satellites in GEO orbit, there would be a much larger number of smaller satellites launched into LEO orbit much closer to Earth. Some of the orbits proposed were as much as 40 times closer to the Earth surface than the geosynchronous Earth orbit (GEO) satellites. The driving idea was to find more cost-efficient ways to design, manufacture, test, and launch these satellites. They all sought to lower the costs of manufacturing and launch these smaller satellites. They also intended to exploit and leverage the "power advantages" and the much reduced signal delay associated with the lower orbits. The so-called path loss was associated with the weakened signal that had to travel back to Earth from an orbit that was some $35,870 \mathrm{~km}(22,230$ miles) in distance away. Latency was the time lag required for the signal travel to reach the ground from a distance almost a tenth of the way to the Moon. 
The signals transmitted from a satellite or sent up to a spacecraft spread out in a circle. This meant that because of the spreading circle, the power loss was a function of the square of the distance traveled. If the satellite was 40 times further away from the Earth, the path loss was not 40 times less, but actually 1600 less (or $40^{2}$ ). This power advantage inherent in low-orbiting satellites could serve to make the user terminals much smaller and less expensive. The plan, in the case of the land mobile satellite systems, was to create satellite handheld phones that could "talk" to these lower Earth orbit (LEO) satellite constellations. The problem with the design of the small satellites for constellations that would completely cover the Earth was that of solid geography. The closer the satellites were to Earth, the more satellites had to be launched to get global coverage. The closer the satellites were to the ground, the lesser the amount of the coverage. This was somewhat the reverse of issue of a radio or television antenna on the ground. The taller a TV or radio antenna extends, the more coverage it has. The Iridium system with one of the lowest planned orbits came up with a design thus ended up with a constellation that required 66 satellites plus at least 8 spares (Iridium Satellite Constellation n.d.).

This shift in design concept to create low Earth orbit constellations of small satellites versus the deployment of just three bigger and higher capacity satellites in GEO orbit in order to create total Earth coverage was a major change in satellite architecture. The earlier model had been to manufacture, meticulously test, and qualify a small number of large, complex, and expensive highly unique satellites that were then launched into GEO orbit. This new model was envisioned to be quite different. James Stuart, the designer of the Teledesic satellite, stated clearly his vision to me as we worked on the Teledesic system design together at the University of Colorado in the late 1980s. "We are going to design and build these satellites like TV sets or Video Cassette Recorders (VCRs). And through large scale production and automated manufacturing of components and maybe even robotic integration we can achieve large economies of scope and scale" (Conversation with James Stuart at the University of Colorado in the late 1980s n.d.).

But despite the optimism that accompanied all of these small satellite constellations, a rather devastating crush of bankruptcies were to follow. Starting in August 1999, Iridium, Globalstar, ICO Ltd., Teledesic, and Orbcomm all declared bankruptcies.

The reasons for these bankruptcies actually differed. In some cases it related to creating totally new markets for new services. In other cases it related to the long time it took to design, manufacture, and deploy a very large network of small satellites and ground control systems plus marketing and selling handsets or small ground antennas before any revenues could be realized. In some cases it related to the performance of the handsets. In other cases it was because the estimated cost of building the satellites was greatly off. The initial estimated cost of deploying the Teledesic satellite system was about $\$ 4$ billion. When the Teledesic system actually went into bankruptcy, the estimated costs had topped $\$ 9$ billion. The bottom line is that small satellite constellations as a business venture that financial investment banks and investors were willing to back became extremely anemic. Some of those that bought up the shares of systems such as Iridium actually tried, 
unsuccessfully so, to sue the backers of those systems for fraud. None of the factors are helpful to the deployment of commercial small satellite constellations.

In fact, some technical and financial experts are suggesting that a number of satellite ventures, including the SpaceX Starlink venture with the most small satellites in their constellation proposals of anyone, might be at risk, due to both underfunding and technical and operational constraints. Satellite analyst Tim Farrar has said: "There are several multi-billion dollar NewSpace satellite projects that could suffer the same fate (i.e. the bankruptcy of Iridium)..... What will that meand for investor perceptions? Will non-NewSpace incumbents benefit? And more fundamentally, is the NewSpace bubble about to burst?" (Farrar 2018).

The failure of one small satellite constellation will not alter the dynamic course and success of "NewSpace" ventures. Space 2.0 is really not about how many small satellites are built but a new way of thinking about space and the creation of new business models. It involves marshalling technological innovation, especially in the areas of IT, digital equipment, and artificial intelligence, to create new more costefficient space systems that can open entirely new markets. Yet at the same time, a large number of bankruptcies of "NewSpace" ventures and failure of small satellite constellations will undoubtedly have a negative effect on the space industry around the world. It is as simple as "Success breeds success, and failure brings other failure."

\section{The Beginnings of Small Satellite Innovation}

But there were other key factors to consider on the small satellite frontiers. Technical experts worked with amateur radio operators to design and build at low cost small satellites for global radio connectivity. These satellites known as Oscar 1, Oscar 2 , etc. proved that low-cost satellites were possible to design and build and that simpler methods and materials could produce viable spacecraft at lower cost (AMSAT Live Oscar Satellite Status Page n.d.). NASA and other space agencies created the concept of the cubesat that was $10 \mathrm{~cm} \times 10 \mathrm{~cm} \times 10 \mathrm{~cm}$ in size.

The initial programs encouraged university students and researchers to design and build their own space experiments. Over the past three decades, the cubesat experimental design process created a widespread interest in space experimentation. This process has now grown and grown. Over time more and more university students, and then even high school and secondary school students, were offered the chance to design and build their own space experiments. This "cubesat" process has now led to thousands of cubesats to be launched into orbit. Today there are a number of companies with websites online where students and interested individuals from around the world can order a standardized cubesat frame and other key components that can be easily fit into one's cubesat project.

Beginning in 2009, Bob Twiggs, a faculty member at Morehead State University, formally proposed a "PocketQube satellite" that was one-eighth the size of a cubesat. This "picosat" configuration that was $5 \mathrm{~cm} \times 5 \mathrm{~cm} \times 5 \mathrm{~cm}$ in size was first flown in November 2013 with four PocketQube satellites packaged together with the Unisat- 
4 launch. The new Vector $\mathrm{R}$ launch vehicle is now expected to offer regular PocketQubeSat launches. The popularity of "PocketQubeSats" is expected to grow as buses, kits, and components are now available online, and this lower-cost alternative to cubesats becomes better known (Pocketqube Satellites n.d.). More information about this new type of "picosat" is provided in the chapter about the "femtosats" and "picosats" that follow.

The miniaturization associated with cubesat projects thus gave rise to a whole new mentality about what is a "satellite" and what can be accomplished by achieving miniaturization of key components in a satellite, the fabrication of quite small spacecraft. The idea was not only to use quite small digital processors, miniaturized sensors, and other very small components but also to be less reliant on extensive, time-consuming, and expensive components. If one of these quite small and much less expensive satellites were to fail, then the idea was to build and launch another one.

What is amazing to some is that all of the critical elements of a satellite can be crammed into the confines of a $10 \mathrm{~cm} \times 10 \mathrm{~cm} \times 10 \mathrm{~cm}$ cube. As shown in Fig. 5 , these elements include power supply, antennas, sensors, or instruments that are the "payload," star trackers or sun sensor, onboard computer and digital memory systems, reaction wheels, and thermal control systems. Some even have a fully functional three-axis stabilization thruster system.

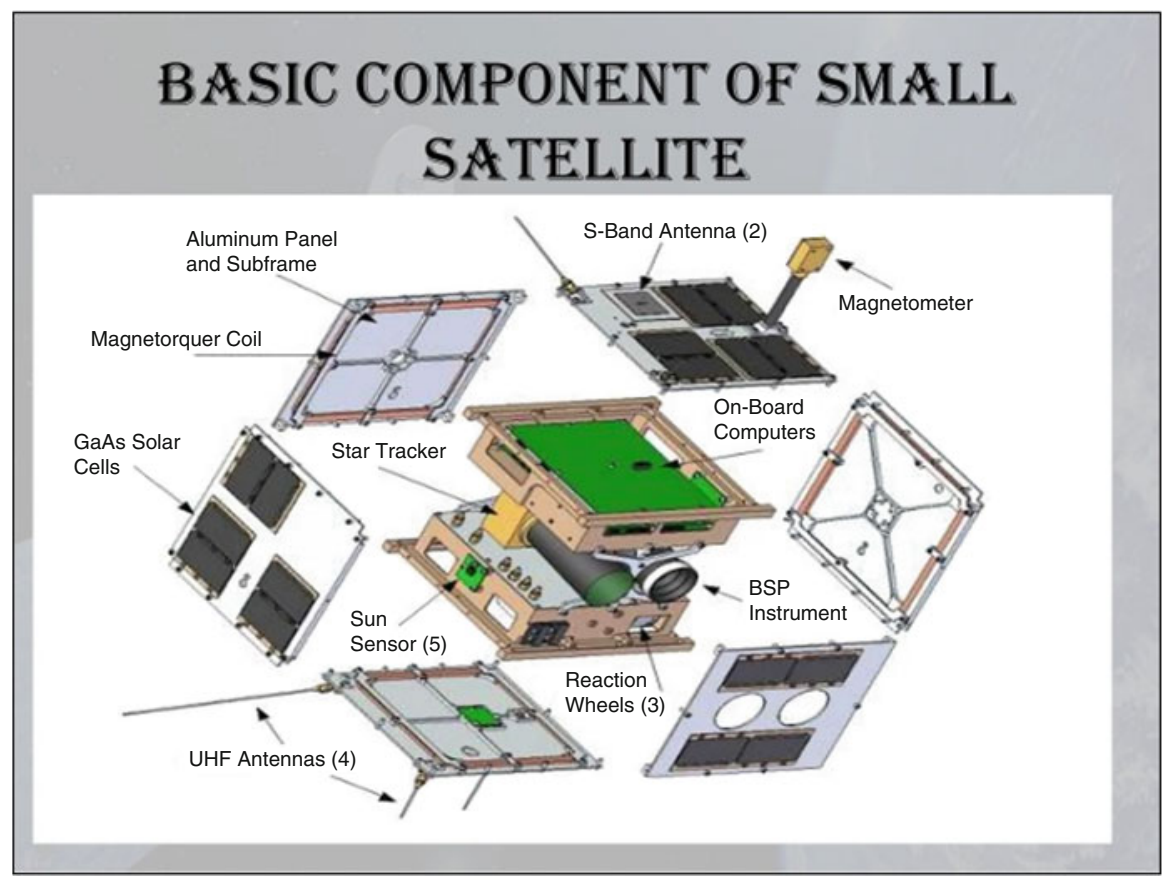

Fig. 5 Exploded view of components of a "cubesat" 
Some have said that this new small satellite approach to space systems was the start of something quite new for the overall industry. Observers look back and say that the "smallsat revolution" was one of the key stimulating factors that have led to what is now called "Space 2.0" or "NewSpace." This new "Silicon Valley"-type thought process was based on a flurry of questions like "what if we did things differently?" There were questions such as the following: How can we reinvent the space industry to make it better, more agile, and entrepreneurial in style? How can we improve on the R\&D processes of the past 30 or 40 years that were largely based on the military-industrial processes and how civilian space agencies have been doing business? How can we do things thinking more like "Silicon Valley" industrial innovators and entrepreneurial business people? How can we create new more agile industrial modes of innovation? How can we do things more quickly with more rapid prototyping? How can we create, build, and test new types of satellites at significantly lower costs, more rapidly, and with less mass? How might we innovate by using the miniaturization of components and "digital processors and sensors" such as those involved with designing digital computers and new electronic and IT industrial products?

If one looks at the launch history of small satellites during the period 2012 through 2018, it can be seen that the predominant source of these new smallsat deployments has been from start-ups who have embraced entirely new models of how to design, test, launch, and operate smallsat system. Planet and Spire Global, two smallsat start-ups, have been responsible for about $40 \%$ of the over 1000 smallsats launched, while the much longer established Orbcomm network deployed less than 2\% (see Fig. 6 that features a graph showing the top 10 commercial launchers of smallsats out of over 90 commercial operators. In addition over 200 nonprofits launched smallsats as well) (Bryce Space and Technology 2019).

Quite parallel to the new way of thinking about the design and manufacture of small satellites came the new way of thinking about creating more efficient launch vehicles, reusable rocket systems, and space planes that are safe enough to carry people on suborbital flights or even into orbit. Suddenly everyone involved in "NewSpace" or what some call "Space 2.0" began to question the way things had been done in the past and began seeking new ways forward (Pelton 2019).

The new commercial mentality has increased launch options and reduced the cost of launch operations. The number of smallsat launches from 2012 to 2018 is over 1300, but over 700 were launched in 2017-2018, and if filings are an indication, that number will continue to increase. Some 104 cubesat systems (most of these being 3-unit systems) were launched on a single Indian polar satellite launch vehicle in February 2017 (PSLVC37 Successfully Launches 104 Satellites in a Single Flight n.d.).

During the period 2012-2016, 68 smallsats were lost due to launch failure, but only one of these came in the 2017-2018 period which showed many more launches and much fewer launch failures (Op cit, Bryce space and technology) (Fig. 7). 


\section{Commercial Smallsats}

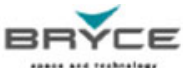

Commercial Operators Launching the Most Smallsats, 2012 - 2018

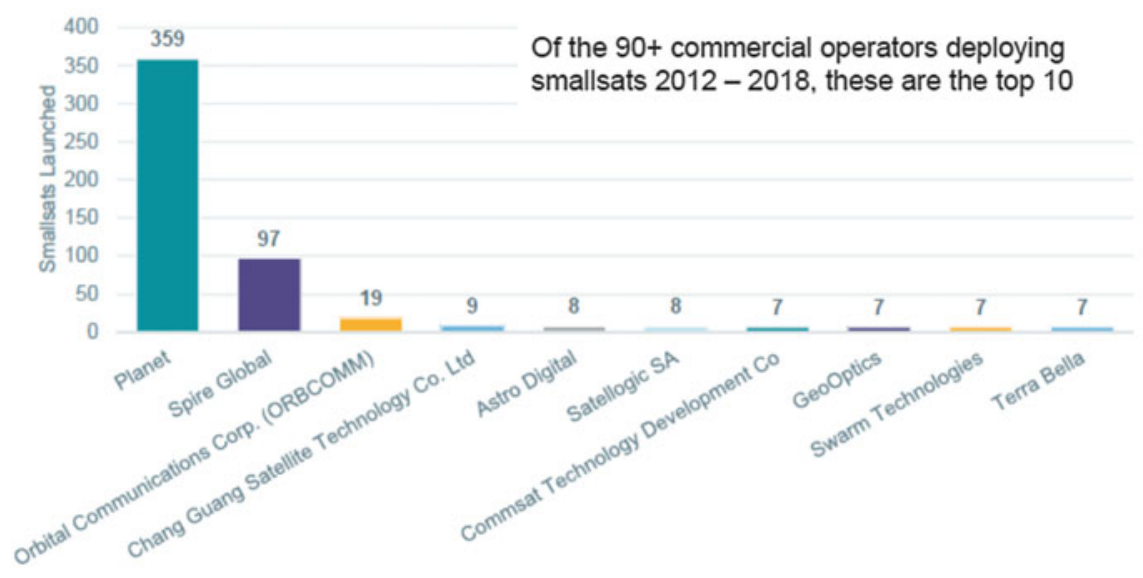

Notes: Planet has operated Terra Bella satellites since acquining Terra Bella in 2017. Unlike the rest of the companies shown, ORBCOMM is a long-established operator, that first deployed satellites in the 1990s. In January 2018, Swarm Technologies launched 4 SpaceBee smallsats without authorization from the FCC.

Smallsats by the Numbers 2019 | Bryce Space and Technology | DC Metro Chicago London

Fig. 6 Commercial satellite operators launching smallsats (2012-2018) (Graphic courtesy of Bryce Space and Technology)

\section{New Ways of Thinking About How to Design, Manufacture, and Launch Satellites}

The way this new way of thinking about satellites in terms of the design, manufacture, and testing actually did not start in Silicon Valley at all. One of the places this new way of thinking started was at the University of Surrey just outside of London. Some very smart engineering faculty such as Professors Barry Evans and Martin Sweeting started to work in small satellite technologies with engineering students at the university in 1981 and was formally incorporated in 1985 as Surrey Satellite Technology, Ltd. This is also now known as the Surrey Space Center and headed by Sir Martin Sweeting. This company has been acquired by Airbus, but it is still a separate company within this very large aerospace company. This company, in 1985, designed and built the University of Surrey-1 (UOS-1) satellite that demonstrated that a small satellite could be designed and built with miniaturized components and high-performance digital processors to accomplish a number of sophisticated functions in orbit within a small and relatively inexpensive satellite. The rest is history.

Today the Surrey Space Center can claim a number of distinctions within the "small satellite world" that includes (i) building and arranging for the launch of 2-4 small satellites per year since its first small satellite projects; (ii) arranging for 


\section{The Big Picture of Smallsats}

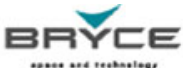

Impact of Launch Failures, 2012 - 2018

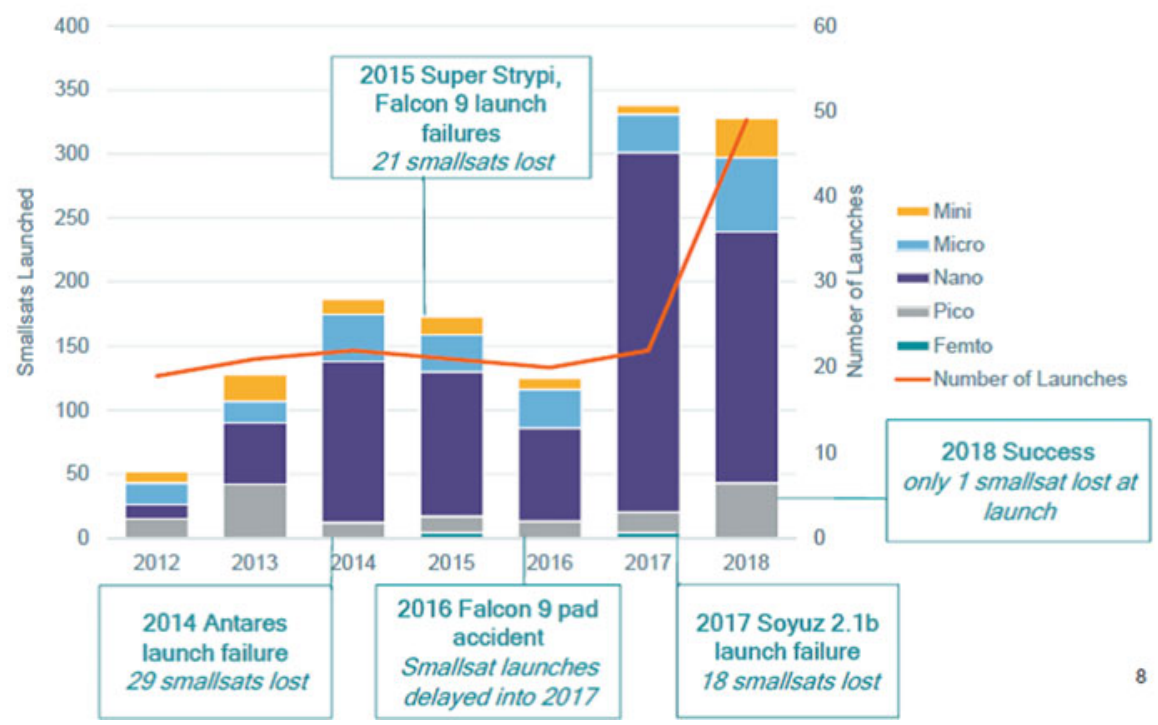

Fig. 7 The Changing profile of small satellite launches (Graphic courtesy of Bryce Space and Technology)

35 launches from 8 different launch sites around the world and manufacturing a total of 60 satellites that have now been launched; (iii) at the current time having 10 satellites and 12 payloads in production; and (iv) conducting 18 satellite training programs for various programs and countries around the world to spread the knowledge about how to design and build small satellites (Surrey Satellite Technology Limited n.d.)

There is also a small satellite research and manufacturing center in the USA. This is known as the Space Dynamics Laboratory (SDL) that is a part of the Utah State University Foundation and is located in Logan, Utah. SDL combines the talents of local aerospace companies with researchers, faculty, and engineering students at Utah State University. SDL has been in existence since 1959 at the very start of the Space Age and has designed and built many small satellites over the years. Utah State University and SDL, together with a wide range of sponsors, and especially the American Institute of Aeronautics and Astronautics, host an annual small satellite conference in August in Logan, Utah (Small Satellite Conference n.d.).

This conference has been running since 1987 when the first conference was held. A complete listing of papers presented at this conferences ever since its founding is available in a special digital library that has been created to preserve the thousands of papers that have been presented at the conference for over three decades. These papers can be accessed via this website: https://digitalcommons.usu.edu/smallsat/. 
This extensive collection of articles can be accessed under such headings as missions, subsystems, structures and materials, signal processing, applications, and more (Digital Library of Papers Presented at the Small Satellite Conference Since 1987, Digital Commons Library, Utah State University, Logan, Utah n.d.).

\section{The Many Different Types of Small Satellites}

As the history of "smallsats" has evolved since the 1980s, it has evolved in many different directions.

First: There have been those that have pursued student-based satellite experiments such as the cubesat program to design very small and low-cost systems. Some of these have been as small as $01-09 \mathrm{~g}$ femtosatellites or picosatellites (i.e., 10 $100 \mathrm{~g}$ ) but are most typically cubesats that might have a mass of about $3-5 \mathrm{~kg}$ in most of these student exercises. Today most student experimental cubesats might be released from the Japanese module on the International Space Station that was built for such smallsat deployments.

Second: Others have developed more sophisticated smallsats for highly sophisticated scientific experiments that are for space agencies or military- or defenserelated agencies. Some of these are in the 1-6-unit cube satellite range, while others are quite a bit larger and in some cases are designed as constellations such as the European Space Agency's three-satellite "Swarm" constellation or NASA's MMS four-satellite constellation. These satellites are currently measuring the Earth's magnetosphere and seeking to detect how magnetic North and magnetic South poles are shifting. Defense agencies are also beginning to build or contract for small satellite constellations for various activities related to their missions.

Third: Groups such as SSTL in Surrey, England, and the Utah State University have assisted countries or organizations that wish to create small satellites for specific applications as they first enter the field of space services. In this case they provide assistance and training for these entities or national space initiatives to create their first satellites for such purposes as data relay, remote sensing, or emergency services.

Fourth: There are a growing number of commercial organizations that are designing larger-scale small satellite constellations for remote sensing (i.e., Planet), position location (i.e., Spire), or communications or data networking (i.e., O3b and SpaceX). These satellites can range from 3-unit cubesats such as the "Doves" of the Planet system for remote sensing up to $500 \mathrm{~km}$ communications satellite in largescale LEO constellations, such as those planned by Space X, Boeing, Telesat, and others.

Fifth: There are those that have decided to place "hosted payload" packages on larger satellites such as the Aireon System that is flying on the Iridium NEXT system. The US Federal Aviation Administration's Office of Space Transportation, known as FAA-AST, has created its own satellite classification system as shown in Table 1. 
Table 1 Definition of types of "smallsats" based on mass

\begin{tabular}{l}
\hline Mass classification system for "smallsats" in kgs $(\mathrm{kg})$ \\
\hline Femto $0.01-0.099 \mathrm{Kg}(10-99 \mathrm{~g})$ \\
\hline Pico $0.1-1(100 \mathrm{~g}$ to $1 \mathrm{~kg})$ \\
\hline Nano $1.1-10$ (generally akin to cubesats) \\
\hline Micro $10.1-200 \mathrm{Kgs}$ \\
\hline Mini $201-600 \mathrm{Kgs}$ \\
\hline Small $601-1200 \mathrm{Kgs}$ \\
\hline Medium $1201-2500 \mathrm{Kgs}$ \\
\hline Intermediate $2501-4200 \mathrm{Kgs}$ \\
\hline Large $4201-5400 \mathrm{Kgs}$ \\
\hline Heavy $5401-7000 \mathrm{Kgs}$ \\
\hline Extra heavy $>7001 \mathrm{Kgs}$
\end{tabular}

Source: FAA AST, The Annual Compendium of Commercial Space Transportation 2018

Table 2 seeks to sort out the great diversity of "smallsats" that now exists. This diversity in size, mass, orbit, power, application, lifetime, functionality, and ability to maneuver and deorbit is confusing (see Table 2).

What is not obvious in the chart is that small satellites are more adept at providing some services than others. It is possible to shrink some key components of a satellite such as digital processors and sensors, but there are limitations with regard to other components. Satellite antennas and their "gain" (or transmission efficiency) are related to their aperture size which correlates to the square of their radii and the inverse square of their radio frequencies. There are limits on power due to the size of solar cell arrays. The area of the photovoltaic exposed to the sun is directly correlated to the power they can generate. The bottom line is that in the case of telecommunication services that depend on power and antenna aperture size, there are constraints on how much can be done with small satellites for communication services.

As noted earlier, there is advantage for small satellites when they are deployed in much lower orbits. A lower altitude orbit does allow the advantage of reduced path loss and reduced transmit beam spreading. But satellites can only sustain a LEO orbit if they are above about $160 \mathrm{~km}$. In fact they actually need to be higher for two reasons. They need to be higher to achieve broader coverage without unacceptably high levels of switching between beams and from satellite to satellite. As one orbit satellites at lower and lower altitudes, the number of satellites needed for global services goes up exponentially and thus the need for switching frequency that affects reliability and continuous sustainability of service. Also satellites deployed in constellations need to be higher in orbit to stay in orbit for many years. Otherwise gravity and atmospheric drag on the satellites would make them deorbit much more quickly. The International Space Station at an altitude of about $300 \mathrm{~km}$, for instance, has to be quite frequently re-boosted to stay in orbit.

The bottom line is that small satellites are well suited to data relay and optical remote sensing, but the usage of small satellites for broadband services such as for television broadcasting and for active radar imaging is really incredibly difficult to 


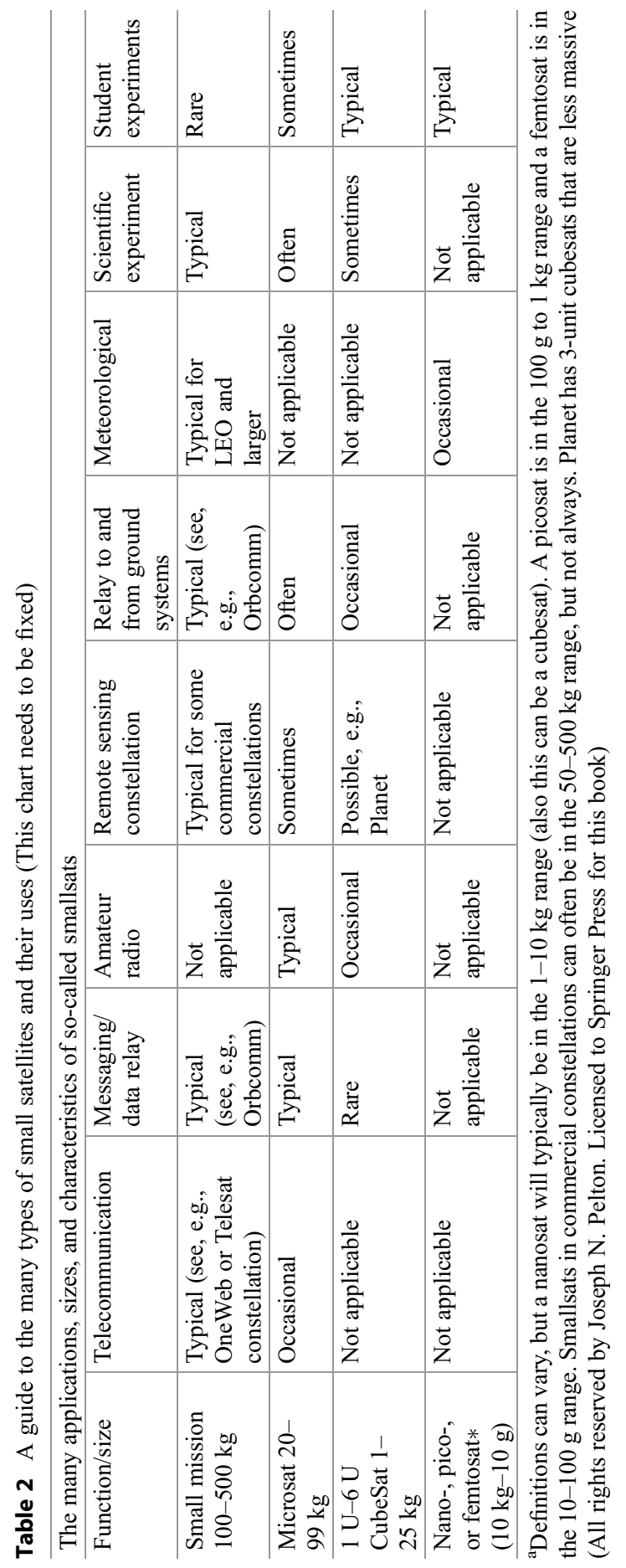


provide from LEO satellite constellations using small and lower-power satellite. This is simply a matter of technical design for both the satellite - based on power limitations - and in the case of home-based television reception installed low-cost user ground terminals.

Broadcast satellite systems to the home to low-cost receiving dishes work very well with consumer dishes that are constantly pointed in a fixed direction and do not have to track the satellite. These television broadcast satellite systems that currently provide over 25,000 television channels worldwide also require spacecraft with large aperture antenna dishes and the ability to transmit at very-high-power levels. Low Earth orbit satellites that travel at high speed across the horizon require tracking capability in the ground system (thus adding cost and complexity) and spacecraft with much higher power, large aperture antennas, and suitable spectrum suited to broadband services. Small satellite constellations can support data relay, digital communications for Internet services, and reasonable throughput data links, but direct to the home television remains best suited to GEO satellites and to user ground systems now installed in millions of homes and systems designed to service apartment buildings and condo units. Indeed most of the small satellite constellations that are currently planned for deployment are largely geared to providing new data connectivity to underserved or unserved regions of the world where Internet-based services are quite limited or even nonexistent.

In the case of remote sensing satellites, optical and ultraviolet sensors can be miniaturized with small sensors and passive collection of light and UV signals from the ground. Such systems can operate quite efficiently from low orbit constellations at modest power levels. Indeed such systems as Planet with hundreds of 3-unit cube satellites now operating can collect data and download it quite efficiently on a global basis. Radar systems are another matter. These types of satellite sensing system require high power that must be transmitted down to the ground and then be reflected back up. This does not mean that radar sat operations cannot be accomplished from smaller satellites, but it does mean that power levels constitute a problem and that this represents a challenge for small satellites in the radar sensing area. Canada is currently deploying its new "RADARSAT Constellation" that is quite a bit smaller than its initial first-generation RADARSAT deployed over a decade ago. This new constellation is composed of three satellites in this new network having relatively high power. Even though they are nearly $500 \mathrm{~kg}$ per satellite and as can be seen, the satellite has rather substantial solar arrays to support significant levels of operational power. The design of these new satellites has borrowed ideas from the smallsat revolution that allows them to be smaller than the original Canadian RADARSAT enables but still allows for their efficient operation. In short, design improvements and more efficient components can also be transferred to the design and operation of larger satellites to make them more cost-effective and easier to launch (RADARSAT n.d.) (see Fig. 8).

Finally, there are satellite services for Precision Navigation and Timing (PNT). In this case the prime constraint is the very high cost of precise atomic clocks that are deployed on these types of satellites. The network of satellites and the size of the constellation are optimized on the basis of effective global coverage and a 


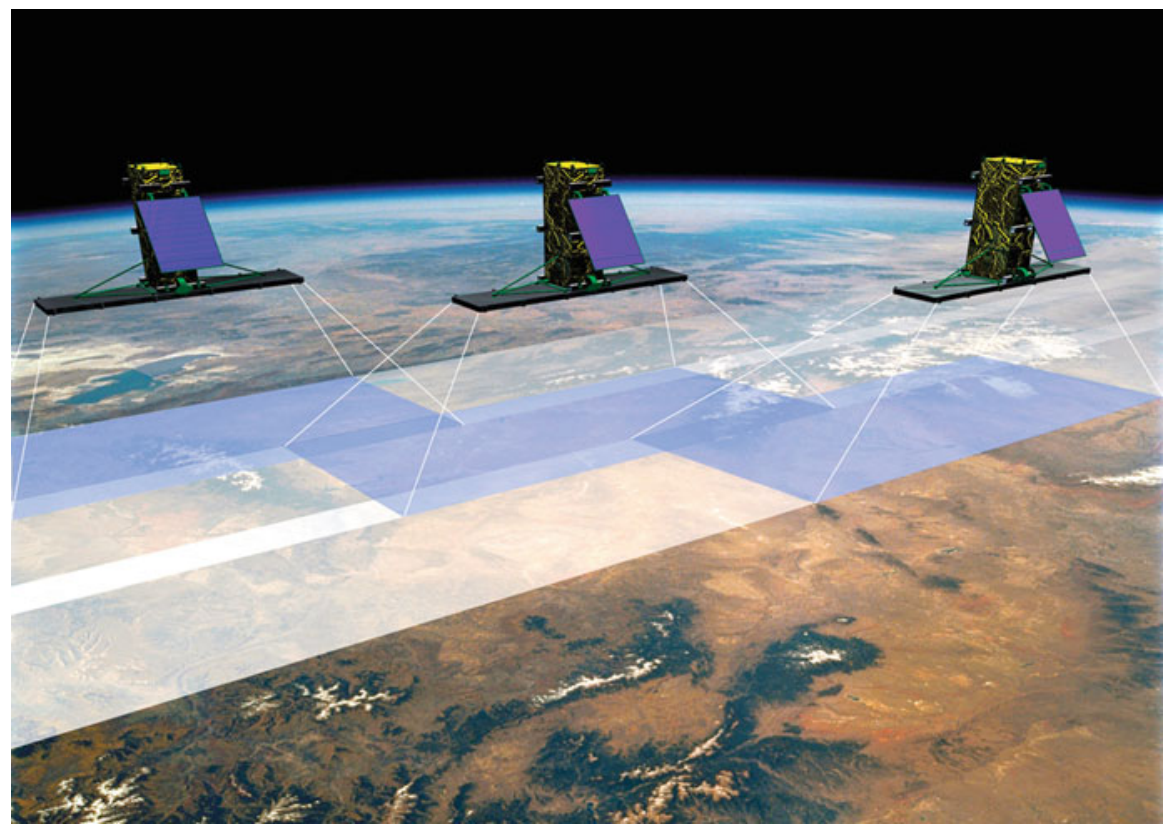

Fig. 8 The new three-satellite Canadian RADARSAT constellation is powerful enough to perform its mission (Graphic courtesy of the Canadian Space Agency)

minimization of the number of clocks that are needed. Deploying of a larger number of smaller satellites in a constellation would drive up costs since it would require the use of more atomic clocks.

The bottom line of this analysis of the relative merits of smallsats, smallsat constellations deployed in LEO orbits, and large and sophisticated satellites generally deployed in GEO orbits is to conclude that there is no single solution that is best. There are different solutions for different applications and services that result in different answers as to the most economic and logical design for satellite services. In some cases small satellite constellations, especially in the case of optical remote sensing, seem to offer a clearly superior answer. Systems, such as the Planet network, seem to provide the most economic and technically sophisticated network design for at least rapid repeat of sensing coverage. Large-scale LEO or MEO networks for digital networking such as represented by $\mathrm{O} 3 \mathrm{~b}$, or systems such as those being deployed by Telesat, Boeing, SpaceX, or others, may prove quite costeffective. The economic feasibility of LEO networks to support corporate enterprise networks for very-high-speed networking using rather large and sophisticated "small satellites" such as that proposed by the LEOSAT system remains to be proven economically. There are questions as to whether LEO smallsat systems designed to provide very high data rate corporate services will be able to provide the needed technical level of standards of service. 


\section{The Challenges of Design, Manufacture, and Testing of Smallsats}

The field of small satellites has led to a host of innovations. This has resulted in a wide range of innovations that has changed a wide range of practices. Many of these innovations have permeated the space industry and affected the practices of space agencies, defense-related space agencies, and traditional aerospace manufacturers. It is interesting to note that some of those planning to fabricate large-scale small satellite constellations include not only SpaceX but also Boeing and AirBus and traditional communications satellite operator Telesat. SES and Intelsat, the two largest traditional satellite operators, have taken more than passing interest. SES has now taken full control and has been expanding the $\mathrm{O} 3 \mathrm{~b}$ constellation. Intelsat came very close to being directly merged with the OneWeb constellation, and this project was not completed due to Softbank withdrawing its offer of financing.

The change caused by small satellite systems ripples through today's space industry and can now be seen throughout the industry. One of the biggest areas of change relates to design, manufacturing, and testing. The traditional way that application satellites such as for communications or remote sensing were procured was through a set of specifications. These could be via a performance set of specifications that left it to the manufacturer to come up with a design that would meet these performance specs. Commercial operators of satellite systems used this form of procurement because it avoided specification changes and overruns. It capped expenses. This approach could also add incentive fees for meeting schedules and reliable performance. The other approach was to use a design specification that spelled out how the satellite was to be designed and spelled out materials and components to be used and even testing processes. This design specifically more typically came from defense agencies. These types of contracts with design specifications were awarded under a cost plus fee basis and constituted a more expensive form of contracting.

The procurement of satellites was seen as a long, arduous, and demanding process with many steps along the way that were stretched out over many years. There were initial design reviews (IDRs) between the procuring party and manufacturer to start the process. These were followed by other design review and ultimately a final design review, followed by actual manufacture of subsystems with testing undertaken, followed by systems integration and final testing. Some of the largest satellite operators had a team of engineers and scientists at the manufacturers' plant to oversee the manufacturing and test of the satellites. Typical production cycles were 36 months to even 48 months for the most sophisticated large-scale satellite. Production and final testing of large GEO satellites of this type were for a limited number of satellites ranging from perhaps three to six in number. Costs were in the tens of millions to even hundreds of millions of dollars, especially for defense-related satellites that might be especially designed with radiation-hardened components.

When the first commercial small satellite constellations were designed and built for Iridium, Globalstar, and Orbcomm, the whole paradigm as to how one should design, manufacture, and test satellites began to change drastically. One might, for example, use the Iridium system as an example of the change. The procurement was 
for 100 satellites, not 3 to 6 , in number. The concept was to design and build the satellite production line that resembled automated production lines and to use 5 sigma quality and validation standards to produce a satellite of the highest quality so that extensive and expensive testing of each and every satellite was no longer necessary. The idea was to produce satellites not over periods of months and years but in terms of days. When the last of the Iridium satellites were rolling off the production lines at the Motorola plant, they were being produced at the rate of one every 4.5 days.

There were many design innovations that were geared not only to provide new and improved functionality to the satellite but also to aid improved manufacturing and testing reliability. These innovations included the use of phased array antennas that eliminated the need for the precise shaping of transmitting and receiving antennas. Also all of the satellite electronics use solid-state amplifiers rather than radio tubes. Remarkably the accelerated manufacturing and scaled-back testing of each satellite produced a remarkable reliability record. The initial Iridium satellite system that was deployed in 1997 and 1998 is only now being replaced by generation NEXT satellites nearly 20 years later, even though they were originally designed for a 6-7-year lifetime. The Iridium system was also designed with intersatellite links to aid sparing and backup as well as allow the entire global network of 66 satellites plus 8 spares to be controlled by two tracking, command, and control Earth station facilities. All of these innovations have been subsequently included in subsequent small satellite constellations.

This is not to say that Iridium was unique. The engineers, scientists, and production personnel that were involved with the design, manufacturing, and testing of other new small satellite systems such as Globalstar and Orbcomm use many of the same innovations to cut costs, increase production times, limit testing costs, and use solid-state technology. Others provided different innovations. The particular design of the Orbcomm satellites allowed cost reductions related to the ability to launch more satellites more efficiently at the same time, use lower-cost Pegasus launch vehicles, and lower stabilization costs. The common factors that are seen throughout the small satellite industry today are the much more rapid mass manufacturing techniques as well as new and much more efficient approaches to quality and validation testing and verification techniques.

Today the innovation in manufacturing and accelerated testing continue apace. Today there are continuing efforts to use automated manufacture of components in the production of smallsats. This includes the concept of additive manufacturing of components to create consistency of production. The key to reliable 3D printing involves high-quality standards for materials that are used in the printers as well as improved printer designs. It is possible that innovations here can also allow components to weigh less and thus reduce the amount of mass to be launched in largescale constellations. The other key issue remains the extent to which one can use offthe-shelf components rather than much more expensive space-qualified materials and components.

In some cases inexperienced designers can jump to conclusions about where, when, and how one might use such off-the-shelf materials for wiring, thruster jets, 
fuels, and digital processors. These might pass tests on the ground but will perform differently in space. This can lead to shorts, fires, or failures in the outer space environment. NASA, ESA, and other space agencies have created test facilities to confirm whether certain materials, wiring, or component elements can be safely utilized in space without overheating, creating a fire, or leading to other hazardous conditions. The key is to recognize that a change in temperature, pressure, or gravity can alter the safety and performance of various materials, wiring, gases, etc. Expert advice needs to be sought when planning to use off-the-shelf materials or non-spacequalified components such as processors, electronic equipment, heat pipes, reaction wheels, fuels and thruster jets, etc.

There are a range of new approaches that are being used with regard to verification and validation testing. One approach that is used with cubesat-type systems such as the "Doves" or 3-unit cubesat remote sensing satellites in the Planet network is to assume that a certain percentage of these satellites will fail but that the constellation has a sufficient population for the network to perform smoothly. Another strategy is to produce enough units at sufficiently low cost to be able to provide sufficient number of spares to replace any satellites that fail. Most small satellite system designers try to do a "type qualification" of their initial satellite under the most stringent conditions. Thus they strive for the highest levels of consistent production so that their first, their tenth, and their hundredth products are produced exactly the same and to the most consistent standards.

There are countervailing influences here. In the case of the Planet production of their smallsat "Doves," there is a team that is consistently seeking to improve their performance. The past generations of satellites, in terms of upgraded performance, were perhaps 4-5 years apart. In the case of Planet, their improved design and upgraded performance may come only months apart. Constant improvements are being sought. The key is to ensure that upgrades in design and performance do not degrade consistency of production, reliability of design, and production quality.

\section{Key Challenges for Small Satellite Constellations Related to Regulatory and International Process Issues}

Clearly there are a number of advantages that come with the deployment of small satellites that are typically deployed in low Earth orbit. These advantages are (i) reduced transmission path loss due to their deployment in low Earth orbit; (ii) use of lower cost components and more off-the-shelf components that reduce costs; (iii) ability to achieve economies of scope and scale not only in their manufacturing but perhaps especially so with regard to accelerated validation and quality testing; and (iv) also their reduced size and mass and lower orbits making them easier to launch and at a lower cost. For instance, a total of 88 Planet satellites were launched on a single Indian Polar Satellite Launch Vehicle in February 2017. In fact additional 16 cubesats were also launched to set a record of 104 satellites being launched at one time on a single rocket (Foust 2017). 
But there are also challenges and difficulties that are also present with the global trend to launch more and more satellites into orbit. There are very real regulatory, spectrum allocation, RF interference, and other constraints that must be addressed.

These difficulties include such problems as (i) orbital debris mitigation and concern about the so-called Kessler syndrome; (ii) radio-frequency coordination and interference avoidance with regard to other LEO satellite constellations and particular concern with regard to interference to satellite in GEO that have protected status; (iii) sufficient RF spectrum and orbital space to accommodate all of the many smallsats now proposed for launch (note: the number of small satellites now proposed for launch exceed 20,000 if they were all placed in orbit); (iv) likely insufficient launch capacity to accommodate the launch of all these systems in a short period of time nor sufficient launch capacity to replenish these satellites when they reach end of life (i.e., 5-7 years); and (v) sufficient ground segment transceivers with tracking capability (i.e., especially electronic tracking capability) to meet the demand for user ground systems.

The detailed market studies that have been carried out concerning these new small satellite consortiums, however, have concluded that only some of these systems will actually be deployed and operated. The Northern Sky Research study has estimated that perhaps only 7000 or so of the minisatellites will be deployed (Northern Sky Research 2018). Further, the Space Works study has concluded that perhaps about 2600 of the nanosat/microsats will finally be deployed in the next 5-8 years (SpaceWorks Announces Release of 2018 Nano/Microsatellite Market Forecast 2018).

These are severe challenges that pose an unprecedented number of problems to be addressed and solved in a short and increasingly urgent period of time for the small satellite industry. Some analysts suggest that many of the proposed systems will not be able to obtain the needed financing to build and launch all of the systems that have been proposed. Thus one of the possible solutions to the various problems noted here might be solved by the simple fact that far fewer of these small satellite constellations will be launched than those that have been proposed. For instance, in the 1980s, the US Federal Communications Commission (FCC) actually approved licenses for 17 new Ka-band satellite systems to be deployed. After the dust had cleared, it turned out that only two of those systems were in fact launched and operationally deployed.

The issues of radio-frequency spectrum and interference represent major issues that are not new. The International Telecommunication Union has sought to find ways to accommodate the growing demand for new application satellite services for many decades. There was an Extraordinary Administrative Radio Conference in 1959 followed by the 1963 Radio Conference that made the first radio-frequency spectrum allocations for NewSpace services. There have been ITU sessions every 4 years since. The latest ITU World Radiocommunication Conference was held in 2019. This represents 15 such ITU World Radiocommunication Conferences since the start of the Space Age. The issues that have been addressed, debated, and sometimes resolved have only increased in scope and intensity of debate. Over the years additional spectrum has been allocated for satellite services. There has been allocation of frequencies in the VHF and UHF bands, largely for mobile, scientific, and military satellite uses. There have been allocations in the C-band, X-band, 
Ku-band, Ka-band, and most recently the Q/V band for civilian and military uses. As the allocations have moved to higher and higher frequencies, larger bands of spectrum, as large as $2500 \mathrm{MHz}$ frequency bands, have been assigned to satellite use. Smaller bands for meteorological, precision navigation and timing, and remote sensing services have also been allocated (Allison 2014).

Yet, at the same time, there has been additional pressure exerted to convert frequencies, such as those in the S-band and the C-band to broadband mobile services to accommodate the needs for new services such as $5 \mathrm{G}$ cellular service.

Other conflicting values have also been exposed, and new regulatory constraints have been imposed at these ITU World Radiocommunication Conferences. This has resulted in assigning "protected status" for GEO satellites vis-a-vis non-geostationary satellites. There has been a division of allocated bands for communications into various specific uses. These have included such specifically defined services as fixed-satellite services (FSS), mobile satellite services (MSS), and broadcasting satellite services (BSS).

Developing countries have felt that the "first come, first served" allotment of frequency use and orbital location registration has worked to their disadvantage. Further countries may agree to global allotments of spectrum for particular uses in their region (i.e., the world of frequency use is divided into three regions, namely, Region 1, Europe and Africa; Region 2, the Americas; and Region 3, Asia and Australasia), but then they add a footnote to say that they take exception for this usage in their own country. Often the world of terrestrial radio usage and the world of satellite communications can come into conflict. The new stratospheric usages associated with UAVs and high-altitude platform systems have complicated spectrum allocation disputes and conflicts even further (Ibid.).

The world of GEO satellites is reasonably straightforward in that there are spacing rules with regard to how close can be space from each other for various types of services and locations registered in the ITU's international frequency register after intersystem coordination procedures are conducted. Satellites that drift north or south from the equator more than $7^{\circ}$ North or South of the Equator are no longer considered in GEO orbit.

The world of small satellite experimental spacecraft and large satellite constellations in LEO orbits becomes ever more confusing in that more and more constellations are being proposed within increasingly complex and larger orbital configurations. Some of these will have intersatellite links, while others do not. There are currently no precise limits as to how exactly many satellites might be launched within a single constellation of small satellites nor precise standards for station-keeping exactness. When the earliest systems like Iridium, Globalstar, and Orbcomm came online with a maximum size of around 70 satellites (i.e., 66 satellites plus spares), the idea of limits on the number of satellites and their proximity might not have seemed important. But today the largest of the SpaceX constellations now proposed for operation in the $\mathrm{Q} / \mathrm{V}$ bands would deploy a rather spectacular number of satellites. 


\section{Regulatory and Technical Innovations to Cope with Orbital Space Debris}

The staggering number of small satellites that have now been proposed for launch in the coming years is in excess of 20,000. This has given rise to very serious concerns about orbital space debris. Figure 9 provides a recent inventory of the debris now in Earth orbit and a breakout of where over 6300 tons of debris now orbits the planet.

And these concerns are not only on the part of experts such as those that monitor satellite orbits and debris such as the US Air Force's Joint Space Operations Center (JSpOC) Mission System (JMS). Actually, the companies that are spending billions of dollars to deploy these huge satellite constellations are themselves concerned about their potential risk and possible liabilities (Op cit Northern sky research, small satellite research, 5th Edition).

The problem of the regulatory guidelines about orbital debris removal is obvious to anyone who examines the "math" associated with the current debris removal guidelines that say debris, including defunct satellites, should be removed from orbit within 25 years of the end of life of satellites. This now out-of-date guideline for debris removal was originally based on the time that debris goes through based on two solar max cycles (which occurs over an 11-year period and creates the maximum atmosphere drag on debris). The LEO small satellites have a lifetime of about 5 7 years. Constellations numbered in the thousands will take years to deploy. The replacement cycle will have to take place within 7 years and so on into the future.

\section{National Aeronautics and Space Administration \\ How Much Junk Is Currently Up There?}
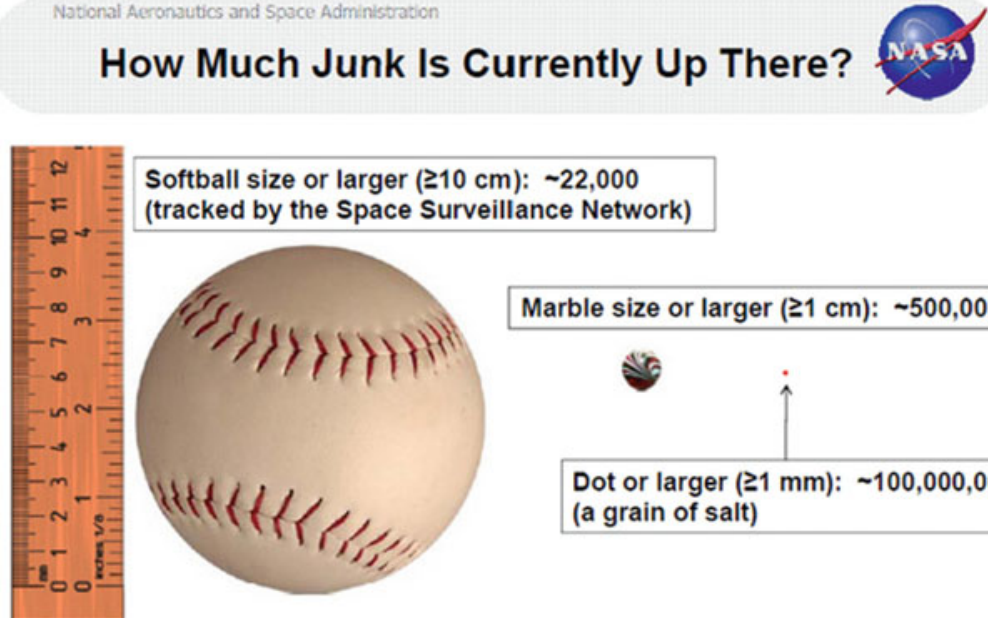

Marble size or larger $(\geq 1 \mathrm{~cm}):-500,000$

- Total mass: $\sim 6300$ tons LEO-to-GEO ( 2700 tons in LEO)

- Debris as small as $0.2 \mathrm{~mm}$ pose a realistic threat to Human Space Flight (EVA suit penetration, Shuttle window replacement)

Fig. 9 NASA status of space debris which will only increase as more constellations are deployed (Graphic courtesy of NASA) 
The removal of satellites based on a 25-year cycle guideline no longer makes sense. The math simply does not work. Controlled deorbit of satellites at the end of life represents a space safety challenge, and there are serious risk elements to be considered. Operators of these systems are themselves advocating new guidelines that are drastically shorter than the current 25 -year guideline.

The current estimates are that there will be a collision in orbit between once in 5 years and once in 10 years, depending on which model (i.e., ESA or NASA) is used. What we do know is that each and every collision contributes to the amount of debris in orbit and especially that in polar orbits and low Earth orbits. Some may believe that since small satellites have smaller cross sections, the chance of a collision is less, but what the small satellites lack in size their sheer volume more than makes up for in terms of on-orbit collision probabilities. The bottom line is that the orbital debris problem and the risk of continuing on-orbit collisions continue to increase in seriousness. This means that active debris mitigation processes are important.

New strategies for coping with orbital debris continue to develop. The abilities for on-orbit servicing and active debris removal or even repurposing of debris in orbit continue to evolve. Currently there are efforts under way to provide new standards and regulatory provisions with regard to rendezvous and proximity operations (RPO). This is an area that needs serious attention as the current debris environment in space continues to worsen (Pelton 2015).

\section{Conclusions and Future Directions}

This Handbook on space satellites seeks to be as comprehensive and far-reaching as possible. It seeks to cover the technology in terms of the satellites; the ground systems and launchers; the applications, services, and markets; the security concerns; and the regulatory, policy, standards, and economics associated with small satellite systems of all types. It seeks to distinguish the smallest small satellites (i.e., femtosats, picosats, nanosats, and cubesats) from the larger microsats and minisats. Experts from around the globe have been recruited to contribute to this Handbook from the academic world, the regulatory world, and the space industry world. Its objective is to provide useful information about the companies that participate in the small satellite industries, the many small satellite constellations that are now in service or planned, as well as the many companies seeking to provide launch services to support the world of small satellites. In light of the fast-moving nature of the industry and many changes that are occurring almost daily, it is recommended that researchers refer to the URL addresses provided in most instances to determine the latest information. Any omissions or key changes not included in this Handbook are entirely unintentional. 


\section{Cross-References}

- Overview of Commercial Small Satellite Systems in the "New Space" Age

- Overview of Cubesat Technology

- Small Satellites for Commercial Systems in Large Scale Constellations

- The Smallest Classes of Small Satellites Including Femtosats, Picosats, Nanosats - and Cubesats

\section{References}

A.L. Allison, The ITU and Managing Satellite Orbital and Spectrum Resources in the 21st Century (Springer Press, Cham, 2014)

AMSAT, Live Oscar Satellite status page (n.d.). https://www.amsat.org/status/. Last accessed 30 May 2019

Bryce Space and Technology, Smallsats by the numbers 2019, p. 6 (Jan 2019a)

Bryce Space and Technology, Smallsats by the Numbers (Feb 2019b)

Conversation with James Stuart at the University of Colorado in the late 1980s (n.d.)

Digital Library of Papers Presented at the Small Satellite Conference Since 1987, Digital Commons Library, Utah State University, Logan, Utah, (n.d.). https://igitalcommons.usu.edu/smallsat/. Last accessed 8 July 2019

T. Farrar, Is the new space bubble about to burst? Room Space Journal 4, 45-47 (2018)

J. Foust, Space news, India sets record with launch of 104 satellites on a single rocket (17 Feb 2017). https://spacenews.com/india-sets-record-with-launch-of-104-satellites-on-a-single-rocket/

Iridium Satellite Constellation (n.d.). https://en.wikipedia.org/wiki/Iridium_satellite_constellation. Last accessed 30 May 2019

Northern Sky Research, Small satellite research, 5th edn (Dec 2018). https://www.nsr.com/research/ small-satellite-markets-5th-edition/

J.N. Pelton, Basics of satellite communications, 1st edn. (International Engineering Consortium, Chicago, 2003)., 2nd Edition 2006

J.N. Pelton, New solutions for the space debris problem (Springer Press, Cham, 2015)

J.N. Pelton, Space 2.0: key trends in the 'new space' industry (Springer Press, Switzerland, 2019)

Pocketqube Satellites (n.d.). https://en.wikipedia.org/wiki/PocketQube. Last accessed 16 Mar 2019

PSLV-C37 Successfully Launches 104 Satellites in a Single Flight (n.d.). https://www.isro.gov.in/ update/15-feb-2017/pslv-c37-successfully-launches-104-satellites-single-flight

RADARSAT, Constellation Mission (n.d.). https://digitalcommons.usu.edu/smallsat/on, http:// www.asc-csa.gc.ca/eng/satellites/radarsat/default.asp. Last Accessed 30 June 2019

Small Satellite Conference (n.d.). https://smallsat.org/. Last accessed 15 June 2019

SpaceWorks Announces Release of 2018 Nano/Microsatellite Market Forecast (30 Jan 2018). https://spaceworkseng.com/spaceworks-announces-release-of-2018-nanomicrosatellite-marketforecast/

Surrey Satellite Technology Limited (n.d.). https://www.sstl.co.uk/about-us. Last accessed 15 June 2019

Teledesic History (n.d.). https://en.wikipedia.org/wiki/Teledesic. Last accessed 30 June 2019 